\title{
Genetic Variation, Heritability, and Diversity Analysis of Upland Rice (Oryza sativa L.) Genotypes Based on Quantitative Traits
}

\author{
Mst. Tuhina-Khatun, ${ }^{1,2}$ Mohamed M. Hanafi, ${ }^{3,4}$ Mohd Rafii Yusop, ${ }^{1}$ M. Y. Wong, \\ Faezah M. Salleh, ${ }^{6}$ and Jannatul Ferdous ${ }^{2}$ \\ ${ }^{1}$ Laboratory of Food Crops, Institute of Tropical Agriculture, Universiti Putra Malaysia (UPM), 43400 Serdang, Selangor, Malaysia \\ ${ }^{2}$ Bangladesh Rice Research Institute, Gazipur 1701, Bangladesh \\ ${ }^{3}$ Laboratory of Plantation Crops, Institute of Tropical Agriculture, Universiti Putra Malaysia (UPM), 43400 Serdang, \\ Selangor, Malaysia \\ ${ }^{4}$ Department of Land Management, Institute of Tropical Agriculture, Universiti Putra Malaysia (UPM), 43400 Serdang, \\ Selangor, Malaysia \\ ${ }^{5}$ Department of Plant Protection, Faculty of Agriculture, Universiti Putra Malaysia, 43400 Serdang, Selangor, Malaysia \\ ${ }^{6}$ Department of Biotechnology and Medical Engineering, Universiti Teknologi Malaysia, 81310 Skudai, Johor, Malaysia
}

Correspondence should be addressed to Mohamed M. Hanafi; mmhanafi@agri.upm.edu.my

Received 27 February 2015; Revised 11 June 2015; Accepted 21 June 2015

Academic Editor: Stefano D’Amelio

\begin{abstract}
Copyright ( 2015 Mst. Tuhina-Khatun et al. This is an open access article distributed under the Creative Commons Attribution License, which permits unrestricted use, distribution, and reproduction in any medium, provided the original work is properly cited.

Upland rice is important for sustainable crop production to meet future food demands. The expansion in area of irrigated rice faces limitations due to water scarcity resulting from climate change. Therefore, this research aimed to identify potential genotypes and suitable traits of upland rice germplasm for breeding programmes. Forty-three genotypes were evaluated in a randomised complete block design with three replications. All genotypes exhibited a wide and significant variation for 22 traits. The highest phenotypic and genotypic coefficient of variation was recorded for the number of filled grains/panicle and yields/plant (g). The highest heritability was found for photosynthetic rate, transpiration rate, stomatal conductance, intercellular $\mathrm{CO}_{2}$, and number of filled grains/panicle and yields/plant (g). Cluster analysis based on 22 traits grouped the 43 rice genotypes into five clusters. Cluster II was the largest and consisted of 20 genotypes mostly originating from the Philippines. The first four principle components of 22 traits accounted for about $72 \%$ of the total variation and indicated a wide variation among the genotypes. The selected best trait of the number of filled grains/panicle and yields/plant (g), which showed high heritability and high genetic advance, could be used as a selection criterion for hybridisation programmes in the future.
\end{abstract}

\section{Introduction}

Upland rice has been gaining popularity, because current high-yielding varieties have led to an increase in genetic vulnerability, a scarcity of water for irrigation, and a breakdown of resistance genes against emerging races of pathogen due to intensive cultivation. In recent decades, the increases in world rice production that have resulted from successes in research and the transfer of modern technology have mainly concerned irrigated high-yielding varieties. Research into upland rice has been very limited and most of the research findings have not been published; therefore, these successes have had virtually no effect on upland rice production. Upland rice comprises $11 \%$ of the total global rice production and is cultivated on about 14 million hectares [1]. It is also important in cropping systems, because of the lack of irrigation facilities and lower cost of production [2].

In Brazil, the mean yield of upland rice is about $2 \mathrm{t} / \mathrm{ha}$, compared to about $5 \mathrm{t} / \mathrm{ha}$ for lowland or irrigated rice [3]. In Nigeria, although the production of rice has increased due to a marked expansion in area, the productivity per unit area has remained at about $1.5 \mathrm{t} / \mathrm{ha}$ [4]. Generally, the grain yields of upland rice are low, from 0.5 to $1.5 \mathrm{t} / \mathrm{ha}$ in Asia, about $0.5 \mathrm{t} / \mathrm{ha}$ in Africa, and from 1.0 to $4.0 \mathrm{t} / \mathrm{ha}$ in Latin America 
[5]. The area planted with rice in Malaysia is estimated to be 672,000 ha and the mean national rice production is 3.66 metric tones/ha [6], of which upland rice is cultivated on about 165,888 ha, with a mean yield ranging from 0.46 to $1.10 \mathrm{t} / \mathrm{ha}[1]$.

To boost the yield potential of upland rice, it is necessary to identify cultivars with improved yield and other desirable agronomic characters, to overcome the global problem of hunger and starvation, especially in African countries [7]. Genetic variation is the basis of plant breeding and provides a great array of genotypes that can be selected to develop new varieties or breeding materials [8]. Variability in terms of genetic divergence for agronomic traits is the key component of breeding programmes for broadening the gene pool of rice and requires reliable estimates of heritability to plan an efficient breeding programme [9]. Knowledge concerning heritability helps plant breeders to predict the nature of the succeeding generation, to make an appropriate selection and to assess the magnitude of genetic improvement through selection [10]. This study was therefore conducted to select potential genotypes and to identify the most important characters for breeding programmes by exploiting the genetic variation, heritability, and diversity analysis of yield and related attributes of 43 upland rice genotypes.

\section{Materials and Methods}

2.1. Experimental Location, Experimental Design, and Planting Material. The experiment was conducted at the net house of the experimental field \#10, at the Universiti Putra Malaysia (UPM) from August to December 2013. The experimental site is located between $3^{\circ} 02^{\prime} \mathrm{N}$ and $101^{\circ} 42^{\prime} \mathrm{E}$ at an altitude of $31 \mathrm{~m}$ above sea level. The study was laid out as a randomised complete block design (RCBD) with three replications. Metal tanks were used for planting the rice genotypes. The size of the tank was $1.85 \mathrm{~m} \times 1.24 \mathrm{~m} \times 0.45 \mathrm{~m}$. The tank was filled with well-pulverised soil.

2.2. Rice Genotypes, Raising of Seedlings, Transplantation, and Management Practices. Forty-three upland rice genotypes (Table 1) obtained from the International Rice Research Institute (IRRI) and Bangladesh Rice Research Institute (BRRI) were used in this study. Thirty sun-dried seeds of each genotype were treated with $70 \%$ ethanol for $90 \mathrm{~s}$ to control seed-borne diseases and were placed on moist filter paper in Petri dishes for germination. After germination, ten-day-old seedlings were transplanted into the tank. Only one seedling per hill was transplanted and each replicate consisted of two hills for each genotype. The interplant and interrow distance was maintained at $20 \mathrm{~cm}$. Management practices such as irrigation, fertilization, weeding, and spraying were performed by following the standard procedures of the IRRI [11].

2.3. Data Collection. The following parameters were considered for data collection: days to flowering (DF, days), days to maturity (DM, days), plant height $(\mathrm{PH}, \mathrm{cm})$, flag leaf length (FL, cm), leaf chlorophyll content at 67 and 97 days after transplanting (CC67 and CC97), photosynthetic rate $\left(P_{N}, \mu \mathrm{mol} / \mathrm{m} / \mathrm{s}\right)$, transpiration rate $(E, \mathrm{mmol} / \mathrm{m} / \mathrm{s})$, stomatal conductance $\left(g_{s}, \mathrm{mmol} / \mathrm{m} / \mathrm{s}\right)$, intercellular $\mathrm{CO}_{2}$ $\left(C_{i}, \mathrm{ppm}\right)$, total number of tillers/plant (TT, no), number of effective tillers/plant (ET, no), panicle length (PL, cm), number of filled grains/panicle (FG, no), number of unfilled grains/panicle (UFG, no), grain length (GL, mm), grain breadth $(\mathrm{GB}, \mathrm{mm})$, grain length/breadth ratio $(L / B)$, straw yield/plant (SY, g), harvest index (HI, \%), 100-grain weight (100 GW, g), and yield/plant $(Y, g)$. The data were recorded based on a standard evaluation system (SES) introduced by the International Rice Research Institute [12].

2.4. Statistical Analyses. The analysis of variance and comparison of means were performed by SAS software version 9.2. Diversity analysis was conducted by NTSYS-PC software (version 2.1) and Minitab software (version 15). The genetic parameters, including the genotypic and phenotypic variance, genotypic and phenotypic coefficient of variance, heritability (broad sense), and the expected genetic advance (GA), were calculated using the formula given by Burton and DeVane (1953) and Johnson et al. (1955) [13, 14].

\section{Results}

3.1. Determination of Genetic Variations. The results revealed a wide range of variability among 43 upland rice genotypes for 22 quantitative traits (Table 2). The phenotypic variance $(\sigma 2 \mathrm{P})$ of all traits was higher than the genotypic variance $(\sigma 2 \mathrm{G})$; similarly, the phenotypic coefficient of variation (PCV) was also higher than genotypic coefficient of variation (GCV). The highest PCV was recorded for the traits FG and $Y$, which were 72.62 and $84.36 \%$, respectively. In contrast, the lowest PCV belonged to the characters CC67 (7.00\%) and CC97 (8.25\%). The GCV ranged from 4.62 (CC67) to $80.07 \%(Y)$. The next highest GCV contained the characters FG (69.73\%), HI (61.60\%), TT (47.17\%), and SY (41.31\%). Similarly, CC97 (5.78\%), GL (7.87\%), DM (8.14\%), and DF (11.14\%) were the traits observed for the next-lowest GCV. Most of the traits in the present study exhibited a high heritability. A heritability of $100 \%$ was recorded for the characters $P_{N}, E, g_{s}$, and $C_{i}$. Furthermore, a higher heritability was also recorded for FG (92.21\%), $Y$ (90.09\%), and GB (85.71\%). In this study, genetic advance (GA) was also calculated and ranged from $6.28 \%$ for CC67 to $156.56 \%$ for $Y$.

3.2. Cluster Analysis. The Euclidean distance was calculated using standardised morphological data and a UPGMA dendrogram was constructed using these values for 43 upland rice genotypes. Five major groups were observed among 43 upland rice genotypes based on multivariate analysis at a 1.08 dissimilarity coefficient value (Figure 1). The value of 1.08 was set only for the convenience of explanation in this case. Cluster II contained the maximum number of genotypes (20), which consisted of $46.51 \%$ of all genotypes, mostly originating from the Philippines. The second highest was cluster III, which consisted of 14 members. Clusters I, IV, and $\mathrm{V}$ consisted of seven, one, and one genotypes, respectively.

3.3. Principal Component Analysis. The results of PCA partly confirmed the findings of cluster analysis: in PCA, the 
TABLE 1: Name, origin, grain color, and status of sample of 43 upland rice genotypes (" $\mathrm{x}$ " means no information about this material).

\begin{tabular}{|c|c|c|c|c|}
\hline Code number & Genotype name & Origin & Seed coat color & Status of sample \\
\hline G1 & Daeng Se Leuad & Thailand & Purple & $\mathrm{x}$ \\
\hline G2 & Khao Gam (NIAW) & Thailand & Purple & Landrace/traditional cultivar \\
\hline G3 & 258 & Liberia & Red & Breeding and inbred line \\
\hline G4 & Black Banni & India & Red & Landrace/traditional cultivar \\
\hline G5 & Blau Noc & Vietnam & Red & Landrace/traditional cultivar \\
\hline G6 & Ble La & Vietnam & Red & Landrace/traditional cultivar \\
\hline G7 & Ble Lia Su & Vietnam & Red & Landrace/traditional cultivar \\
\hline G8 & Chirikata 2 & India & Red & $\mathrm{x}$ \\
\hline G9 & Choke Tang & Vietnam & Red & $\mathrm{x}$ \\
\hline G10 & Chokoto 14 & Brazil & Red & $\mathrm{x}$ \\
\hline G11 & IPPA & Bhutan & Red & Landrace/traditional cultivar \\
\hline G12 & IR 3257-13-56 & Philippines & Red & Breeding and inbred line \\
\hline G13 & IR 5533-13-1-1 & Philippines & Red & Breeding and inbred line \\
\hline G14 & IR 5533-14-1-1 & Philippines & Red & Breeding and inbred line \\
\hline G15 & IR 5533-15-1-1 & Philippines & Red & Breeding and inbred line \\
\hline G16 & IR 5533-50-1-10 & Philippines & Red & Breeding and inbred line \\
\hline G17 & IR 5533-55-1-11 & Philippines & Red & Breeding and inbred line \\
\hline G18 & IR 5533-56-1-12 & Philippines & Red & Breeding and inbred line \\
\hline G19 & IR 5533-PP 854-1 & Philippines & Red & Breeding and inbred line \\
\hline G20 & IR 5533-PP 856-1 & Philippines & Red & Breeding and inbred line \\
\hline G21 & IR 9559-3-1-1 & Philippines & Red & Breeding and inbred line \\
\hline G22 & IR 9559-4-1-1 & Philippines & Red & Breeding and inbred line \\
\hline G23 & IR 9559-5-3-2 & Philippines & Red & Breeding and inbred line \\
\hline G24 & IR 9559-PP 871-1 & Philippines & Red & Breeding and inbred line \\
\hline G25 & IR 9669-22-2-6 & Philippines & Red & Breeding and inbred line \\
\hline G26 & IR 9669-23-12-7 & Philippines & Red & Breeding and inbred line \\
\hline G27 & IR 9669-PP 823-1 & Philippines & Red & Breeding and inbred line \\
\hline G28 & IR 9669-PP 830-1 & Philippines & Red & Breeding and inbred line \\
\hline G29 & IR 9669-PP 836-1 & Philippines & Red & Breeding and inbred line \\
\hline G30 & Ja Hau & Thailand & Red & Landrace/traditional cultivar \\
\hline G31 & Ja La Shau & Thailand & Red & Landrace/traditional cultivar \\
\hline G32 & Ja Loy & Thailand & Red & Landrace/traditional cultivar \\
\hline G33 & Ja No Naq & Thailand & Red & Landrace/traditional cultivar \\
\hline G34 & Beu E-Soo & Thailand & Purple & Landrace/traditional cultivar \\
\hline G35 & C & Ivory Coast & Red & Released/improved/advanced cultivar \\
\hline G36 & Padi Beleong & Malaysia & Red & $\mathrm{x}$ \\
\hline G37 & Padi Kalopak & Malaysia & Red & $\mathrm{x}$ \\
\hline G38 & F1 seed $(\mathrm{BR} 16 \times$ Karingam $)$ & Malaysia & White & F1 seed \\
\hline G39 & BR 24 & Bangladesh & White & Improved cultivar \\
\hline G40 & BR26 & Bangladesh & White & Improved cultivar \\
\hline G41 & BRRI dhan 42 & Bangladesh & White & Improved cultivar \\
\hline G42 & BRRI dhan 43 & Bangladesh & White & Improved cultivar \\
\hline G43 & BRRI dhan 48 & Bangladesh & White & Improved cultivar \\
\hline
\end{tabular}

genotypes also clustered into five groups (Figure 2), with only few differences between groups I and III compared to cluster analysis. This demonstrates that the data obtained from this experiment were accurate, precise, and reliable. The PCA analysis showed that the first four principal components accounted for about $72.1 \%$ of the total variation and exhibited a very high correlation among them. The first, second, third, and fourth principle components explained about $35.7 \%$, $53.1 \%, 64.5 \%$, and $72.1 \%$ of the variation observed in the eigenvector analysis (Table 3). In the first PC: PH (0.29), FL (0.29), PL (0.29), FG (0.31), and HI (0.30) were the most important contributing traits; similarly, $P_{N}(0.43), E(0.40)$, $g_{s}(0.39)$, and GB (0.40) were the important parameters of the second PC. 
TABLE 2: Estimation of genetic parameters of 22 agronomic, physiological, yield, and yield contributing traits.

\begin{tabular}{|c|c|c|c|c|c|c|c|c|c|}
\hline Traits & Mean & MSG & MSE & $\sigma 2 \mathrm{G}$ & $\sigma 2 \mathrm{P}$ & PCV (\%) & GCV (\%) & $h_{B}^{2}(\%)$ & GA (\%) \\
\hline DF & 85.66 & 296.95 & 23.77 & 91.07 & 114.84 & 12.51 & 11.14 & 79.3 & 20.44 \\
\hline $\mathrm{DM}$ & 116.58 & 287.93 & 17.53 & 90.13 & 107.66 & 8.90 & 8.14 & 83.72 & 15.34 \\
\hline $\mathrm{PH}$ & 103.88 & 1053.97 & 76.71 & 325.75 & 402.46 & 19.31 & 17.37 & 80.94 & 32.2 \\
\hline $\mathrm{FL}$ & 30.67 & 169.4 & 25.73 & 47.89 & 73.62 & 27.98 & 22.56 & 65.05 & 37.49 \\
\hline $\mathrm{TT}$ & 10.24 & 85.03 & 6.38 & 23.33 & 29.71 & 53.23 & 47.17 & 78.53 & 86.11 \\
\hline CC67 & 41.13 & 15.52 & 4.68 & 3.61 & 8.29 & 7 & 4.62 & 43.55 & 6.28 \\
\hline СС97 & 42.79 & 24.71 & 6.34 & 6.12 & 12.46 & 8.25 & 5.78 & 49.12 & 8.35 \\
\hline$P_{N}$ & 9.14 & 30.38 & 0 & 10.13 & 10.13 & 34.82 & 34.82 & 100 & 71.73 \\
\hline$E$ & 3.03 & 1.74 & 0 & 0.58 & 0.58 & 25.13 & 25.13 & 100 & 51.78 \\
\hline$g_{s}$ & 0.11 & 0.004 & 0 & 0.001 & 0.001 & 28.75 & 28.75 & 100 & 59.22 \\
\hline$C_{i}$ & 227.98 & 5375 & 0.4 & 1791.5 & 1791.9 & 18.57 & 18.57 & 99.98 & 38.24 \\
\hline SY & 16.09 & 151.72 & 19.19 & 44.18 & 63.37 & 49.48 & 41.31 & 69.72 & 71.06 \\
\hline HI & 21.26 & 540.16 & 25.55 & 171.53 & 197.08 & 66.03 & 61.60 & 87.04 & 118.40 \\
\hline ET & 6.83 & 29.98 & 3.48 & 7.76 & 11.24 & 49.09 & 40.79 & 69.04 & 69.81 \\
\hline PL & 21.04 & 57.34 & 12.45 & 14.96 & 27.41 & 24.88 & 18.38 & 54.58 & 27.98 \\
\hline FG & 33.2 & 1653.29 & 45.3 & 535.99 & 581.29 & 72.62 & 69.73 & 92.21 & 137.94 \\
\hline UFG & 35.03 & 693.11 & 92.54 & 200.19 & 292.73 & 48.84 & 40.39 & 68.39 & 68.81 \\
\hline GL & 6.35 & 0.826 & 0.067 & 0.25 & 0.317 & 8.87 & 7.87 & 78.86 & 14.4 \\
\hline GB & 2.39 & 0.394 & 0.02 & 0.12 & 0.14 & 15.66 & 14.49 & 85.71 & 27.64 \\
\hline$L / B$ & 2.7 & 0.429 & 0.034 & 0.13 & 0.164 & 15 & 13.35 & 79.27 & 24.49 \\
\hline $100 \mathrm{GW}$ & 1.99 & 0.366 & 0.03 & 0.11 & 0.14 & 18.8 & 16.67 & 78.57 & 30.43 \\
\hline Y & 4.44 & 39.33 & 1.39 & 12.64 & 14.03 & 84.36 & 80.07 & 90.09 & 156.57 \\
\hline
\end{tabular}

Note: MSG, mean square of accessions; MSE, mean square of error; $\sigma 2 \mathrm{G}$, genotypic variance; $\sigma 2 \mathrm{P}$, phenotypic variance; PCV, phenotypic coefficient of variance; $\mathrm{GCV}$, genotypic coefficient of variance; $h^{2}$, heritability in broad sense; GA, genetic advance.

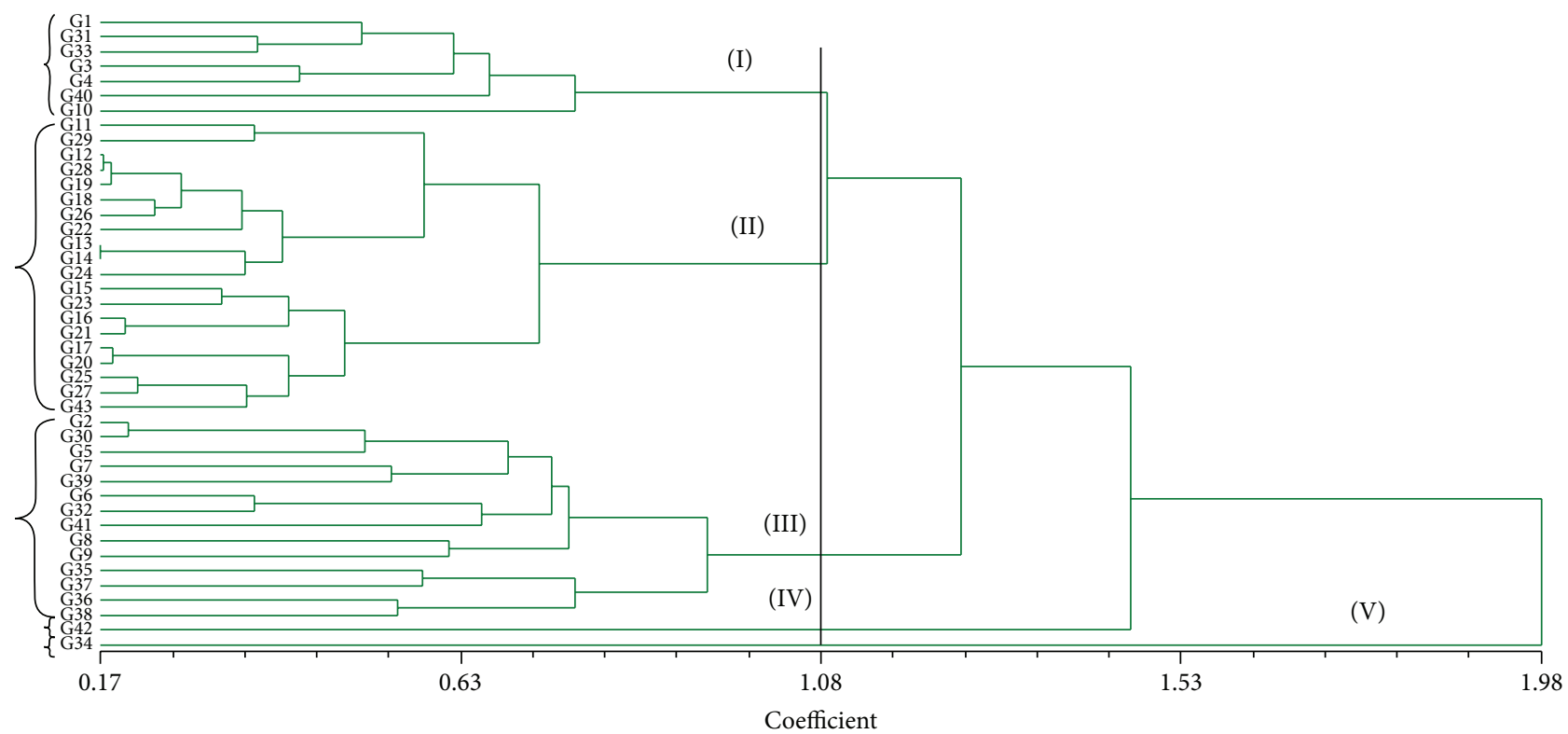

FIGURE 1: Cluster analysis of 43 upland rice genotypes based on morphological, physiological, and yield associated characters. 


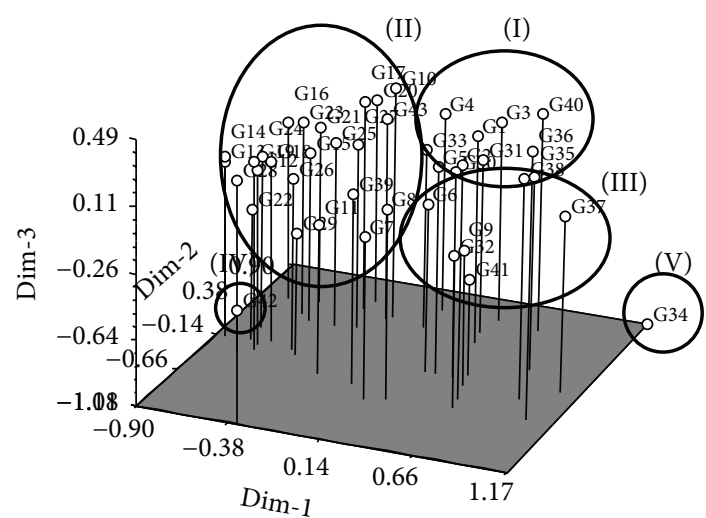

FIgURE 2: Three-dimensional graph of 43 upland rice genotypes based on morphological, physiological, and yield associated characters (principal component analysis).

\section{Discussion}

The genetic analysis of quantitative traits is a prerequisite for plant breeding programmes, which can lead to a systemic method of design and to the appropriate planning of plant breeding strategies. The current study suggests that the PCV was higher than the GCV for all traits. This was also the case for all the traits observed in another study [7], which reported that the environmental effect on any trait is indicated by the magnitude of the differences between the genotypic and phenotypic coefficients of variation; large differences reflect a large environmental effect, whereas small differences reveal a high genetic influence. In this study, the small differences between the PCV and GCV for most of the traits, such as $\mathrm{DF}, \mathrm{DM}, P_{N}, E, g_{s}, C_{i}$, and GL, represented some degree of environmental influence on the phenotypic expression of these characters. It also suggests that selection based on these characters would be effective for future crossing programmes. The other traits, which showed a higher difference between PCV and GCV, indicated that the environmental effect on the expression of those traits is higher and that selection based on these characters is not effective for further yield improvement. The highest PCV was recorded for FG and $Y$. High GCV and PCV for FG and $Y$ were also recorded by the following researchers [15-18]. The variables $P_{N}, E, g_{s}$, and $C_{i}$ revealed $100 \%$ heritability, which indicated the presence of additive gene action. This also showed that selection based on these characters would be more effective and efficient than the use of other traits for segregating generations in future breeding programmes, which indicated an exploitable amount of variation. A study conducted by Jahn et al. [19] reported that the percentage variance for photosynthesis was highest among 20 diverse rice varieties based on 14 quantitative traits. However, they observed a low variance for transpiration and stomatal conductance. Genetic variation and diversity studies for the aforementioned traits are scarce for upland and lowland rice. However, many researchers have observed the $P_{N}, E$, and $g_{s}$ capacity of rice varieties under drought stress and control conditions and showed that all these parameters decrease under water stress in rice [20,21].
TABLE 3: Eigenvectors and eigenvalues of the first four principle components of 22 traits.

\begin{tabular}{|c|c|c|c|c|}
\hline Variable & $\mathrm{PC} 1$ & PC2 & PC3 & PC4 \\
\hline Eigenvalue & 7.86 & 3.81 & 2.50 & 1.66 \\
\hline Variation (\%) & 35.7 & 17.4 & 11.4 & 7.6 \\
\hline Cumulative (\%) & 35.7 & 53.1 & 64.5 & 72.1 \\
\hline $\mathrm{DF}$ & -0.289 & 0.022 & -0.033 & -0.047 \\
\hline $\mathrm{DM}$ & -0.314 & 0.044 & 0.006 & 0.095 \\
\hline CC67 & 0.201 & 0.143 & -0.051 & 0.076 \\
\hline CC97 & 0.237 & 0.224 & -0.072 & 0.169 \\
\hline$P_{N}$ & -0.07 & 0.433 & 0.012 & 0.193 \\
\hline$E$ & -0.128 & 0.398 & -0.027 & -0.127 \\
\hline$g_{s}$ & -0.152 & 0.393 & -0.059 & -0.187 \\
\hline$C_{i}$ & -0.077 & -0.036 & -0.125 & -0.493 \\
\hline $\mathrm{PH}$ & 0.293 & 0.029 & -0.13 & -0.106 \\
\hline $\mathrm{FL}$ & 0.289 & 0.074 & -0.065 & -0.064 \\
\hline $\mathrm{TT}$ & -0.27 & -0.021 & -0.361 & -0.001 \\
\hline ET & -0.145 & -0.109 & -0.517 & -0.02 \\
\hline PL & 0.291 & 0.078 & -0.002 & 0.042 \\
\hline FG & 0.313 & -0.087 & -0.037 & -0.109 \\
\hline UFG & 0.199 & -0.08 & 0.076 & 0.011 \\
\hline GL & 0.073 & 0.178 & -0.194 & 0.506 \\
\hline GB & 0.08 & 0.399 & 0.012 & -0.171 \\
\hline$L / B$ & -0.019 & -0.322 & -0.131 & 0.45 \\
\hline $100 \mathrm{GW}$ & 0.152 & 0.275 & -0.256 & 0.198 \\
\hline$Y$ & 0.217 & -0.093 & -0.404 & -0.224 \\
\hline SY & -0.115 & -0.008 & -0.494 & -0.009 \\
\hline $\mathrm{HI}$ & 0.298 & -0.092 & -0.134 & -0.13 \\
\hline
\end{tabular}

Note: PC1, first principle component; PC2, second principle component; PC3, third principle component; and PC4, four principle component.

The FG and $Y$ showed a very high heritability coupled with the highest genetic advance, suggesting that these traits were mainly under genetic control and that they can be scored by their phenotypic performance. In a separate study of 19 upland rice accessions, Vange [4] estimated the heritability and genetic advance to be high, for the parameters days to $50 \%$ heading, days to maturity, flag leaf area, panicle weight, panicle length, no branches per panicle, no seeds/panicle, and seed weight/panicle at seed yield. High heritability (more than $60 \%$ ) and high genetic advance (more than $20 \%$ ) for leaf chlorophyll content, number of productive tillers per plant, panicle weight and number of grains per panicle, and 1,000grain weight were recorded by Laxuman et al. [22].

The 43 upland rice genotypes clustered into five groups based on the dendrograms of cluster analysis and PCA. The groupings of hierarchical cluster analysis exhibited a similar dendrogram topology and cluster membership to that produced using PCA analysis, thereby confirming the accuracy of the constructed dendrogram. Likewise, Worede et al. [23] calculated a similar clustering pattern for hierarchical cluster analysis and principal component analysis for 24 rice 
genotypes. The multivariate analysis of the quantitative traits identified the most similar genotypes as $13 \times 14$ and $12 \times 28$, based on the dissimilarity coefficient, suggesting that hybridisation within these genotypes will not be effective, as their genetic make-up is almost similar. However, crossing between genotypes $13 \times 34$ and $14 \times 34$ will be effective, as these genotypes were identified as being most divergent. The Euclidian distance showed that the clusters were mostly formed based on the origin or geographical area of the genotypes. The genotypes from the same geographical origin mostly grouped together; however, the less frequent genotypes from different origins also grouped within the same cluster. Fifty-eight rice varieties grouped into four clusters based on 18 morphological characters in a study by Ahmadikhah et al. [24]. Rahman et al. [25] also divided 21 rice varieties into five clusters based on 14 physiological traits. Principal component analysis helps to understand how the genotypes of similar categories group together compared to dissimilar ones. The results of PCA can clarify or verify the cluster analysis; if the results of one analysis support those of another, this confirms that the data are more precise and accurate. The presence of strong differences among 43 upland rice genotypes in the present study was also further confirmed by PCA. The first four principal components accounted for $72 \%$ of the total variation, which indicated a very strong correlation among the characters being studied. The first PC, which solely contributed to $35.7 \%$ of the variation, was the most significant. Accordingly, in the first PC, the traits $\mathrm{PH}, \mathrm{FL}, \mathrm{PL}, \mathrm{FG}$, and $\mathrm{HI}$ were important in separating the genotypes due to their high loadings. Similarly, Worede et al. [23] explained $61.2 \%$ of the total variability using the first and second PCs. Approximately, $82.7 \%$ of the total variation among 32 upland rice varieties was also noted by Lasalita-Zapico et al. [26]. For the selection of parents, genetic diversity is one of the important decisive factors [15]. Our investigation highlighted that genotypes originating from the Philippines could be hybridised with genotypes from Malaysia, Thailand, Vietnam, India, or Bangladesh and vice versa, to create a broader genetic variation for yield and other favorable characters.

\section{Conclusions}

The present study showed the existence of a considerable level of diversity among the 43 upland rice genotypes. The highest heritability recorded for the parameters photosynthetic rate, transpiration rate, and number of filled grains/panicle and yields/plant demonstrates that these traits could be successfully transferred to offspring, if selection for these characters is performed in the hybridisation programme. The aforementioned traits of number of filled grains/panicle and yields/plant showed a very high genetic advance, which implies that these characters could be used to select upland accession genotypes for a notable improvement in cultivation in changing environments, particularly under conditions of water scarcity in the tropics. Furthermore, crossing the genotypes IR 5533-13-1-1 × Beu E-Soo and IR 5533-14-1-1 × Beu E-Soo could result in heterotic expression and a large variability in the segregating generation.

\section{Conflict of Interests}

The authors declare that there is no conflict of interests regarding the publication of this paper.

\section{Acknowledgments}

Mst. Tuhina Khatun would like to express her gratitude to the Organization for Women in Science for the Developing World (OWSD) to award her to pursue Ph.D. program in Universiti Putra Malaysia. The research was supported by the Long-Term Research Grant Scheme (LRGS), Food Security Project, Ministry of Education, Malaysia (LRGS 5525001). Mst. Tuhina Khatun extends her special thanks to the authority of the Bangladesh Rice Research Institute for providing deputation during her study period.

\section{References}

[1] M. Sohrabi, M. Y. Rafii, M. M. Hanafi, A. S. N. Akmar, and M. A. Latif, "Genetic diversity of upland rice germplasm in malaysia based on quantitative traits," The Scientific World Journal, vol. 2012, Article ID 416291, 9 pages, 2012.

[2] N. K. Fageria, M. C. S. Carvalho, and F. C. dos Santos, "Response of upland rice genotypes to nitrogen fertilization," Communications in Soil Science and Plant Analysis, vol. 45, no. 15, pp. 2058-2066, 2014.

[3] N. K. Fageria, O. P. Moraes, and M. J. Vasconcelos, "Upland rice genotypes evaluation for phosphorus use efficiency," Journal of Plant Nutrition, vol. 36, no. 12, pp. 1868-1880, 2013.

[4] T. Vange, "Biometrical studies on genetic diversity of some upland rice (Oryza sativa L.) accessions," Nature and Science, vol. 7, no. 1, 2009.

[5] IRRI, Major Research in Upland Rice, Varietal Diversity and Morpho-Agronomic Characteristics of Upland Rice, International Rice Research Institute, Los Baños, Philippines, 1975.

[6] Z. Fahmi, B. Abu Samah, and H. Abdullah, "Paddy industry and paddy farmers well-being: a success recipe for agriculture industry in Malaysia," Asian Social Science, vol. 9, no. 3, pp. 177181, 2013.

[7] K. A. Osman, A. M. Mustafa, F. Ali, Z. Yonglain, and Q. Fazhan, "Genetic variability for yield and related attributes of upland rice genotypes in semi arid zone (Sudan)," African Journal of Agricultural Research, vol. 7, no. 33, pp. 4613-4619, 2012.

[8] P. Pandey, P. John Anurag, D. K. Tiwari, S. K. Yadav, and B. Kumar, "Genetic variability, diversity and association of quantitative traits with grain yield in rice (Oryza sativaL.)," Journal of Bio-Science, vol. 17, no. 1, pp. 77-82, 2009.

[9] M. Akinwale, G. Gregorio, F. Nwilene, B. Akinyele, S. A. Ogunbayo, and A. C. Odiyi, "Heritability and correlation coefficient analysis for yield and its components in rice (Oryza sativa L.)," African Journal of Plant Science, vol. 5, pp. 207-212, 2011.

[10] M. Tuhina-Khatun, M. A. Newaz, and M. A. A. Bari, "Combining ability and heritability estimates in F2 diallel population of spring wheat under interacting environments," Bangladesh Journal of Agricultural Sciences, vol. 34, pp. 75-82, 2007.

[11] S. O. Oikeh, F. E. Nwilene, T. A. Agunbiade et al., Growing Upland Rice: A Production Handbook, Africa Rice Center (WARDA), http://www.irri.org/. 
[12] International Rice Research Institute, Standard Evaluation System for Rice, International Rice Research Institute, Manila, Philippines, 4th edition, 1996.

[13] G. W. Burton and E. H. DeVane, "Estimating heritability in tall fescue (Festuca arundinacea) from replicated clonal material," Agronomy Journal, vol. 45, no. 10, pp. 478-481, 1953.

[14] H. W. Johnson, H. F. Robinson, and R. E. Comstock, "Estimates of genetic and environmental variability in soybeans," Agronomy Journal, vol. 47, no. 7, pp. 314-318, 1955.

[15] M. S. Mazid, M. Y. Rafii, M. M. Hanafi, H. A. Rahim, and M. A. Latif, "Genetic variation, heritability, divergence and biomass accumulation of rice genotypes resistant to bacterial blight revealed by quantitative traits and ISSR markers," Physiologia Plantarum, vol. 149, no. 3, pp. 432-447, 2013.

[16] P. Pandey and P. J. Anurag, "Estimation of genetic parameters in indigenous rice," Advances in Agriculture \& Botanics, vol. 2, no. $1,2010$.

[17] S. H. Habib, M. K. Bashar, M. Khalequzzaman,, M. S. Ahmed, and E. S. M. H. Rashid, "Genetic analysis and morpho-physiological selection criteria for traditional Biroin Bangladesh rice germplasms," Journal of Biological Sciences, vol. 5, no. 3, pp. 315318, 2005.

[18] R. Saravanan and N. Senthil, "Genotypic and phenotypic variability, heritability and genetic advance in some important traits in rice," The Madras Agricultural Journal, vol. 84, pp. 276-277, 1997.

[19] C. E. Jahn, J. K. Mckay, R. Mauleon et al., "Genetic variation in biomass traits among 20 diverse rice varieties," Plant Physiology, vol. 155, no. 1, pp. 157-168, 2011.

[20] H. M. Akram, A. Ali, A. Sattar, H. S. U. Rehman, and A. Bibi, "Impact of water deficit stress on various physiological and agronomic traits of three Basmati rice (Oryza sativa L.) cultivars," Journal of Animal and Plant Sciences, vol. 23, no. 5, pp. 1415-1423, 2013.

[21] L. Ding, Y. R. Li, Y. Li, Q. R. Shen, and S. W. Guo, "Effects of drought stress on photosynthesis and water status of rice leaves," Chinese Journal of Rice Science, vol. 28, no. 1, pp. 65-70, 2014.

[22] L. Laxuman, P. Salimath, and H. Shashidhar, "Analysis of genetics variability in interspecific backcross inbred lines in rice (Oryza sativa L.)," Karnataka Journal of Agricultural Sciences, vol. 23, pp. 563-565, 2010.

[23] F. Worede, T. Sreewongchai, C. Phumichai, and P. Sripichitt, "Multivariate analysis of genetic diversity among some rice genotypes using morpho-agronomic traits," Journal of Plant Sciences, vol. 9, no. 1, pp. 14-24, 2014.

[24] A. Ahmadikhah, S. Nasrollanejad, and O. Alishah, "Quantitative studies for investigating variation and its effect on heterosis of rice," International Journal of Plant Production, vol. 2, pp. 297308, 2008.

[25] M. M. Rahman, M. G. Rasul, M. K. Bashar, M. A. Syed, and M. R. Islam, "Parent selection for transplanted aman rice breeding by morphological, physiological and molecular diversity analysis," Libyan Agriculture Research Center Journal International, vol. 2, pp. 26-28, 2011.

[26] F. C. Lasalita-Zapico, J. A. Namocatcat, and J. L. Cariño-Turner, "Genetic diversity analysis of traditional upland rice cultivars in Kihan, Malapatan, Sarangani Province, Philippines using morphometric markers," Philippine Journal of Science, vol. 139, no. 2, pp. 177-180, 2010. 

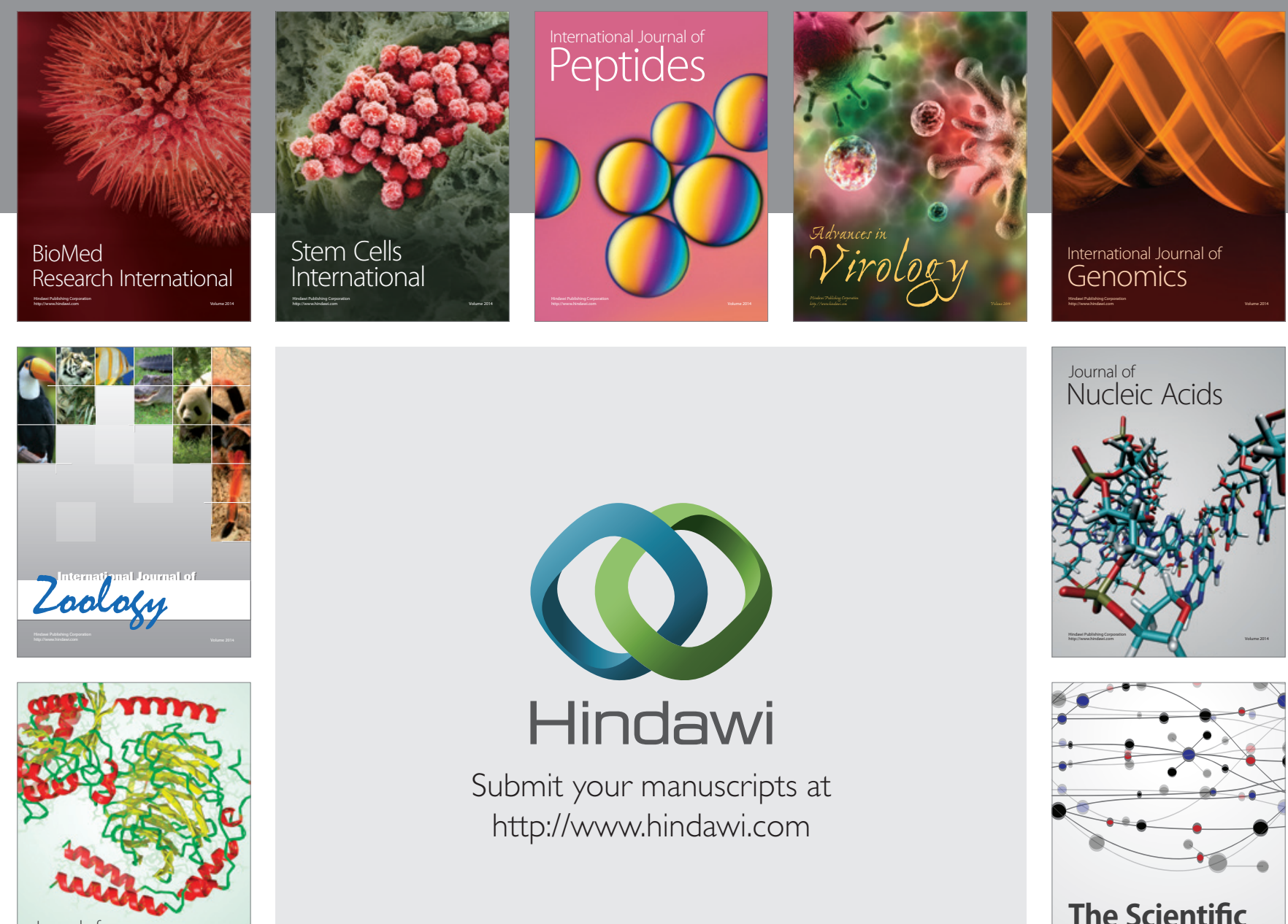

Submit your manuscripts at

http://www.hindawi.com

Journal of
Signal Transduction
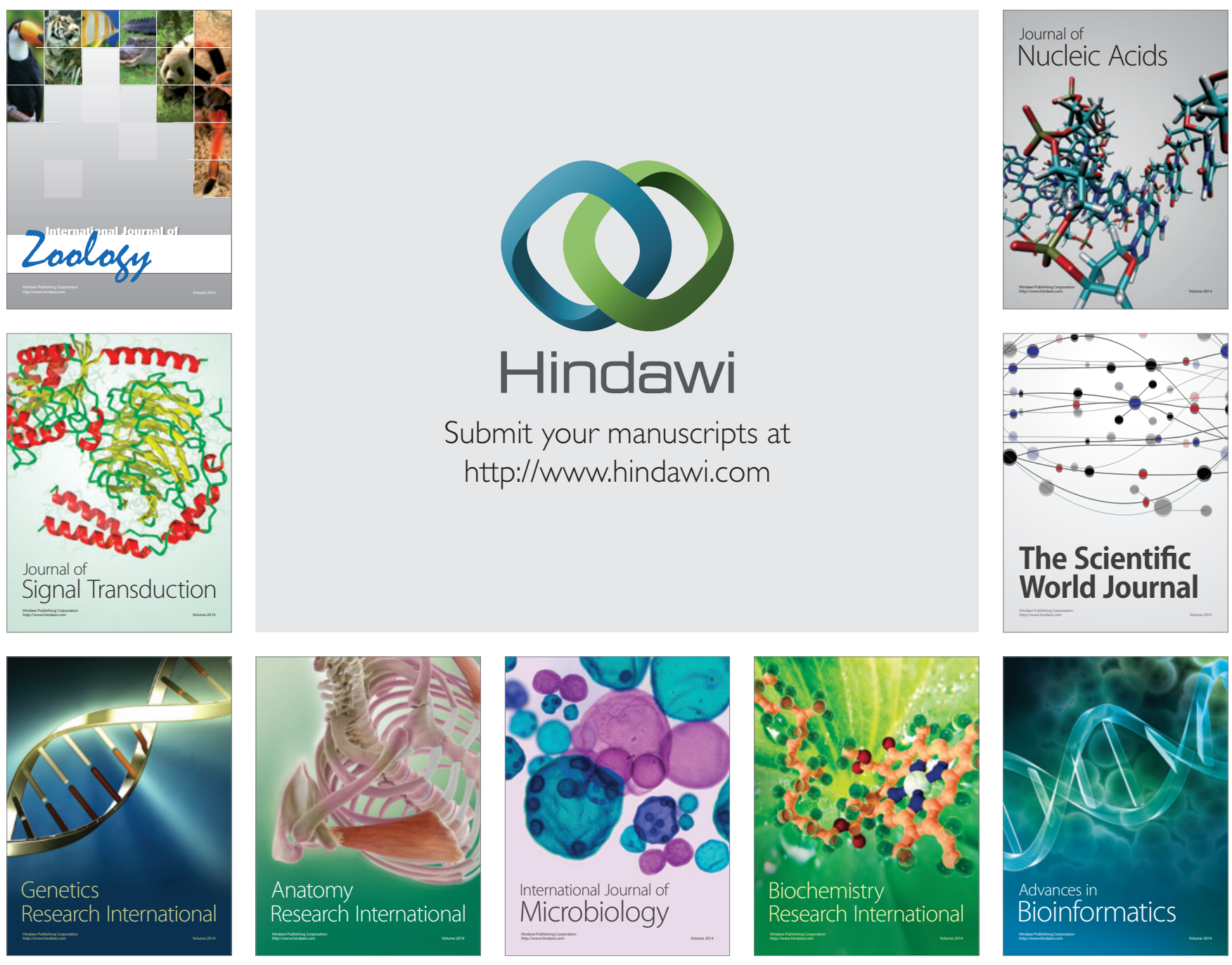

The Scientific World Journal
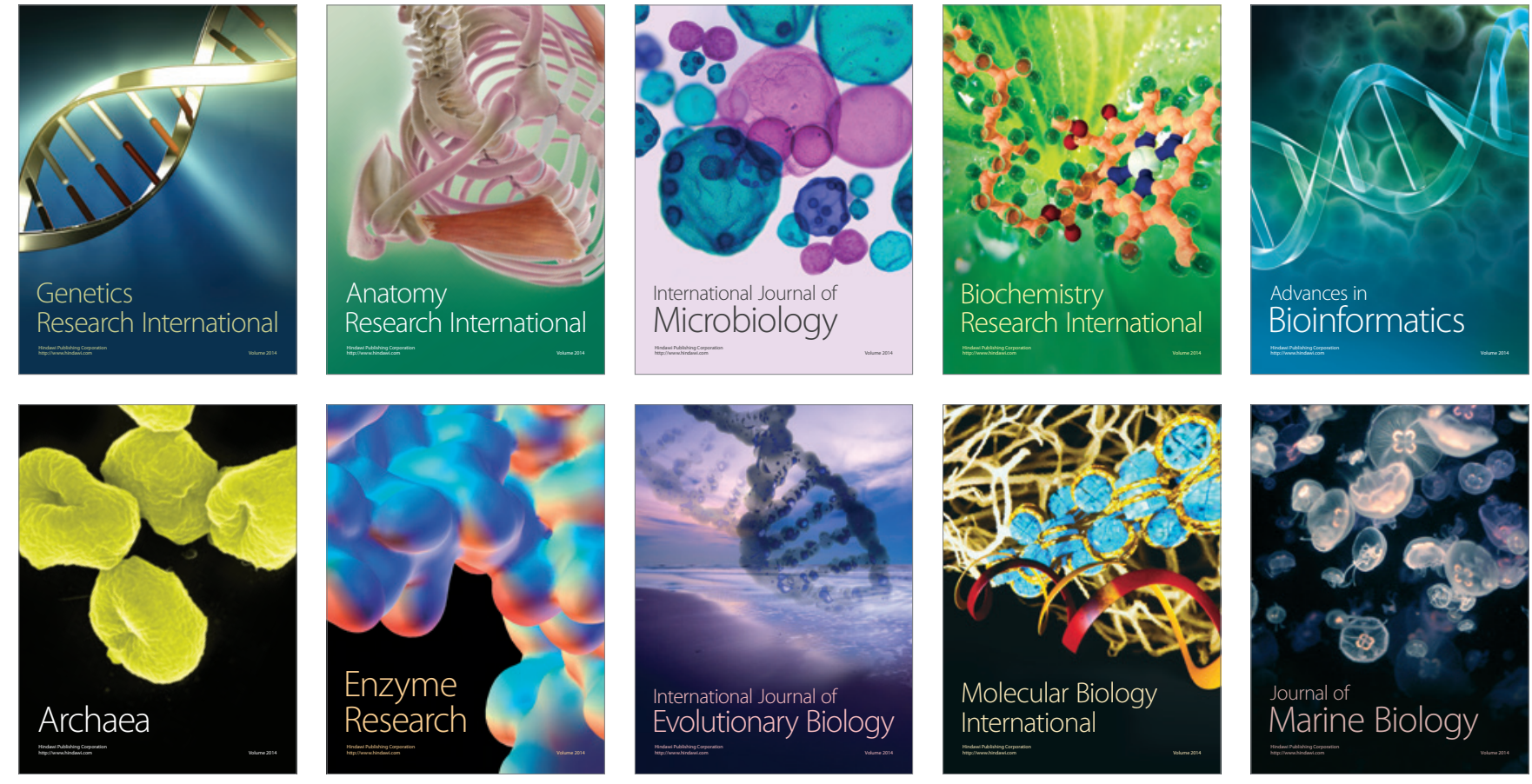